Article

\title{
Biological Control of Phototrophic Biofilms in a Show Cave: The Case of Nerja Cave
}

\author{
Valme Jurado ${ }^{1} \oplus$, Yolanda del Rosal ${ }^{2}$, Jose Luis Gonzalez-Pimentel ${ }^{1,3}$, Bernardo Hermosin ${ }^{1}$ and \\ Cesareo Saiz-Jimenez ${ }^{1, *}$ \\ 1 Instituto de Recursos Naturales y Agrobiologia, CSIC, 41012 Sevilla, Spain; vjurado@irnase.csic.es (V.J.); \\ pimentel@irnas.csic.es (J.L.G.-P.); b.hermosin@csic.es (B.H.) \\ 2 Instituto de Investigacion Cueva de Nerja, 29787 Nerja, Spain; yolanda@cuevadenerja.es \\ 3 Current address: HERCULES Laboratory, Evora University, 7000-809 Evora, Portugal \\ * Correspondence: saiz@irnase.csic.es
}

Received: 20 March 2020; Accepted: 14 May 2020; Published: 16 May 2020

\begin{abstract}
Cyanobacteria and microalgae are usually found in speleothems, rocks and walls of show caves exposed to artificial lighting. These microorganisms develop as biofilms coating the mineral surfaces and producing aesthetic, physical and chemical deterioration. A wide number of physical, chemical and environmental-friendly methods have been used for controlling the biofilms with different results. Natural biological control has been suggested by some authors as a theoretical approach but without direct evidence or application. Here we report the finding of a natural biological control of phototrophic biofilms on the speleothems of Nerja Cave, Malaga, Spain. The formation of plaques or spots where the phototrophic microorganisms disappeared can be assumed on the basis of processes of predation of bacteria, amoebas and some other organisms on the phototrophic biofilms. This study aims at investigating the potentialities of the biological control of phototrophic biofilms in caves, but the originality of these data should be confirmed in future studies with a larger number of biofilm samples in different ecological scenarios.
\end{abstract}

Keywords: phototrophic biofilms; show caves; biological control; bacteria; cyanobacteria; amoeba

\section{Introduction}

Traditionally, caves have been considered as extreme environments characterized by low nutrient inputs. Although this may be possible in a few caves, most of the show caves cannot be considered extreme or oligotrophic environments because natural factors are often modified due to different anthropogenic impacts, being one of the most evident the installation of electrical lighting to facilitate visits. In fact, when caves are illuminated by natural or artificial lighting, phototrophic microorganisms become predominant. Under these conditions, complex communities develop on speleothems, walls and ground, mostly composed of cyanobacteria and algae, heterotrophic bacteria and fungi, and other eukaryotic organisms embedded in a matrix of extracellular polymeric substances. In further steps, mosses, ferns and other plants may also colonize caves. Examples of these communities have been studied in artificially illuminated show caves and catacombs, because their unconstrained growth can induce damage on valuable archeological or natural rock surfaces [1-3].

The biofilms cause aesthetic, physical and chemical damage [4,5], subject of great concern in general, and in particular in cases of caves with rock art paintings [6]. In addition, this invasion of foreign microorganisms induces great changes on the autochthonous microbial population, adapted to minimal inputs of $\mathrm{C}$ and $\mathrm{N}$, and on the cave ecology.

A wide array of methods has been proposed to control and/or eliminate phototrophic biofilms in show caves, including physical, chemical and biological procedures. Physical methods comprise: 
(i) the mechanical removal of biofilms by brushing and subsequent washing with pressurized water; (ii) the reduction of light intensity, and (iii) the use of ultraviolet radiation. Chemical methods include the use of sodium and calcium hypochlorite, hydrogen peroxide or commercial biocides. A detailed discussion of pros and cons were presented by Mulec and Kosi [7] and Baquedano et al. [8]. Some of these methods were tested in Cueva del Tesoro, a limestone cave in Rincon de la Victoria, Spain, depicting abundant biofilms coating the cave walls and speleothems [1]. The most effective treatments were sodium hypochlorite and hydrogen peroxide, but for the final cleaning hydrogen peroxide was adopted due to the absence of chemical residues on the rock [1].

Yet, there is no general consensus on the type of biological methods to be applied in cleaning processes. Albertano et al. [2] suggested the use of quorum-sensing molecules and siderophores, whereas Mulec and Kosi [7] proposed biological antagonists like genetically modified viruses. However, to our knowledge field-based experiments have not been conducted thus far.

Trophic relationships among components in phototrophic biofilms can be deduced by analyzing their composition; however, they have rarely been investigated in detail. Usually, most reports rely on a list of cyanobacteria and algae on speleothems but without establishing the trophic interactions among the different biofilm components [9-12]. Biofilms can suffer a loss of cells through different processes: grazing, erosion, abrasion, and sloughing [13]. The most relevant mechanisms to cave biofilms are likely grazing and sloughing, the first by predation of bacteria and protozoa, and the second by periodic loss of large patches of biofilms by drying processes.

By adopting advanced high throughput sequencing techniques, we aimed at investigating the composition of phototrophic biofilms within the Nerja Cave to highlight the potential role of natural biological control. To achieve this aim, we compared the composition of biofilms showing extensive detachments and/or rounded areas without photosynthetic microorganisms, with homogeneous biofilms on two speleothems, in order to understand the mechanisms involved in the process of detachment.

\section{Materials and Methods}

Nerja Cave was discovered in 1959 and open to public visits in 1960. The cave attracts about 450,000 visitors per year due to its location in Costa del Sol, a major tourist area, at $50 \mathrm{~km}$ from Malaga, Spain. The cave has an extension of almost $5 \mathrm{~km}$, but the tourist trail is restricted to one-third of the cave. The cave is protected as a site of cultural interest due to its rock art paintings [3]. In addition to the cave entrance, this cave has two sinkholes that connect with the outside. The natural lighting that penetrates through the two sinkholes and the electric lighting installed in the tourist trail have allowed the development of photosynthetic-based biofilms on cave speleothems and walls. Currently, the electric lighting system consists of a trail, which runs along a circular route of about $600 \mathrm{~m}$, a scenic lighting, and an emergency system. Some biofilms coating the speleothems close to light sources show extensive detachments and/or rounded areas without phototrophic microorganisms.

The biofilm samples were collected in November 2018 from two speleothems located in the so-called Tourist Galleries (Figure 1A). Unfortunately, sampling was restricted to a very limited number of samples due to the cataloging of the cave as a site of cultural interest. However, we believe that the data provided were representative of the cave microbiome and shed light on biofilms composition and trophic interactions.

Microclimatic data registered in the Tourist Galleries showed that cave air temperature ranges from 19.8 to $18.1{ }^{\circ} \mathrm{C}$ with a mean value of $19.0{ }^{\circ} \mathrm{C}$, the relative humidity ranges from 98.6 to $67.5 \%$ with a mean value of $89.4 \%$ and the air $\mathrm{CO}_{2}$ ranges from 1313 to $360 \mathrm{ppm}$ with a mean value of $679 \mathrm{ppm}$ [3]. Both biofilms studied in this work were exposed to white low pressure commercial fluorescent lamps (Roblan, Casarrubios del Monte, Spain, model ES27, 18W with a color temperature of $4845 \mathrm{~K}$ and $1030 \mathrm{~lm}$ ), located $1 \mathrm{~m}$ away from speleothems. All the samples were collected at the same time by carefully scraping the biofilms with sterile scalpels; samples were kept at $-80^{\circ} \mathrm{C}$ until processing. 
A total of six samples were collected from two speleothems displaying detachment patterns. In the sampling site 1 (Figure 1B), three areas were collected: with biofilms (1A), with and without biofilms (1B), and a zone of rounded detachments (1C). Sampling site 2 (Figure 1C) comprised: a biofilm sample (2A), an extensive detachment (2B), and the interface between the biofilm and the detached zone (2C).
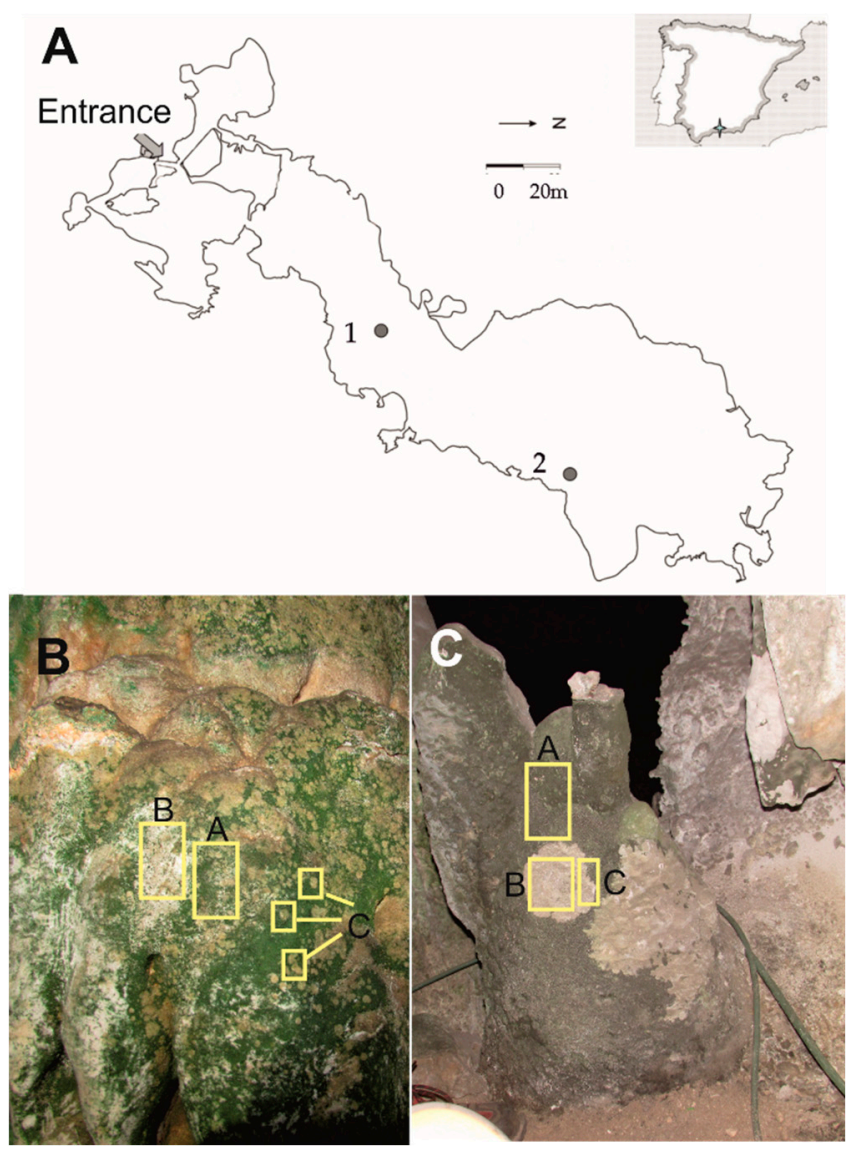

Figure 1. Sampling of biofilms in Nerja Cave speleothems. (A) Map of part of the cave and location of the sampling sites. (B) Sampling site 1. (C) Sampling site 2.

Genomic DNA was extracted from 250-500 mg of biofilms, using the FastDNA SPIN Kit for soil (MP Biomedicals, Illkirch, France) according to the manufacturer's instructions. The DNA concentrations, ranging from 6.0-104.0 ng/ $\mu \mathrm{L}$ depending on each sample, were quantified by using a Qubit 2.0 fluorometer (Invitrogen, Carlsbad, CA, USA).

The extracted DNA of all samples was analyzed by Next Generation Sequencing (NGS). We investigated the bacterial V3 and V4 regions of the 16S rRNA gene and V4 region of the 18S rRNA gene using Illumina MiSeq and $2 \times 250$ paired-end sequencing, according to the Illumina metagenomic library preparation protocol used by Macrogen (Seoul, Korea). The primer sequences used in this study were 341F (CCTACGGGNGGCWGCAG) and 805R (GACTACHVGGGTATCTAATCC) for bacteria, Reuk454FWD1 (CCAGCASCYGCGGTAATTCC) and V4r (ACTTTCGTTCTTGAT) for eukaryotes [14].

Raw data were processed in QIIME 1.9.1. Quality control and trimming were performed using FASTQC (http://www.bioinformatics.babraham.ac.uk/projects/fastqc/) and Trimmomatic (0.36 version), respectively. Paired-end reads were assembled using PEAR. Operational Taxonomic Units (OTUs) were clustered at $97 \%$ cutoff using UCLUST. SILVA database for bacteria and eukaryotes was used to assign the taxonomic classification of each 16S rRNA and 18S rRNA gene sequences with a threshold of $80 \%$.

Alpha_diversity.py command was employed for alpha-diversity. Taxonomic analyses of prokaryotic communities were represented through heat-maps built in R using gplots package [15]. 
Represented samples in heat-maps were reordered with dendrograms based on the row and column mean values as described by the authors. The raw reads were deposited into the NCBI Sequence Read Archive (SRA) database under accession number PRJNA611930.

\section{Results}

Table 1 indicates that the microbial communities of the samples taken from the speleothems coated by phototrophic biofilms collected in Nerja Cave were almost entirely composed of members of Bacteria, with percentages ranging between $100.0 \%$ and $99.7 \%$. The Archaea were practically non-existent, reaching $0.2 \%$ in sample $1 \mathrm{~A}$ and $0.3 \%$ in sample $1 \mathrm{C}$. The percentage of unassigned community members was zero.

Table 1. Kingdoms distribution in phototrophic biofilms from Nerja Cave.

\begin{tabular}{ccccccc}
\hline Kingdom & 1A & 1B & 1C & 2A & 2B & 2C \\
\hline Bacteria & 99.8 & 100.0 & 99.7 & 100.0 & 100.0 & 100.0 \\
Archaea & 0.2 & 0.00 & 0.3 & 0.0 & 0.0 & 0.0 \\
\hline
\end{tabular}

The phototrophic communities of Nerja Cave were composed of 12 phyla with percentages greater than 1\% (Figure 2). The most abundant phyla were Firmicutes, Proteobacteria and Cyanobacteria. Members of the phylum Cyanobacteria contribute to the green color of biofilms, due to the chlorophyll and its photosynthetic function, while other phyla are mainly composed of heterotrophic bacteria. Firmicutes was widely represented in sample 1 and Proteobacteria in sample 2. Cyanobacteria were abundant in samples 1A, 2A and 2C, which corresponded to the areas of epilithic phototrophic biofilms.

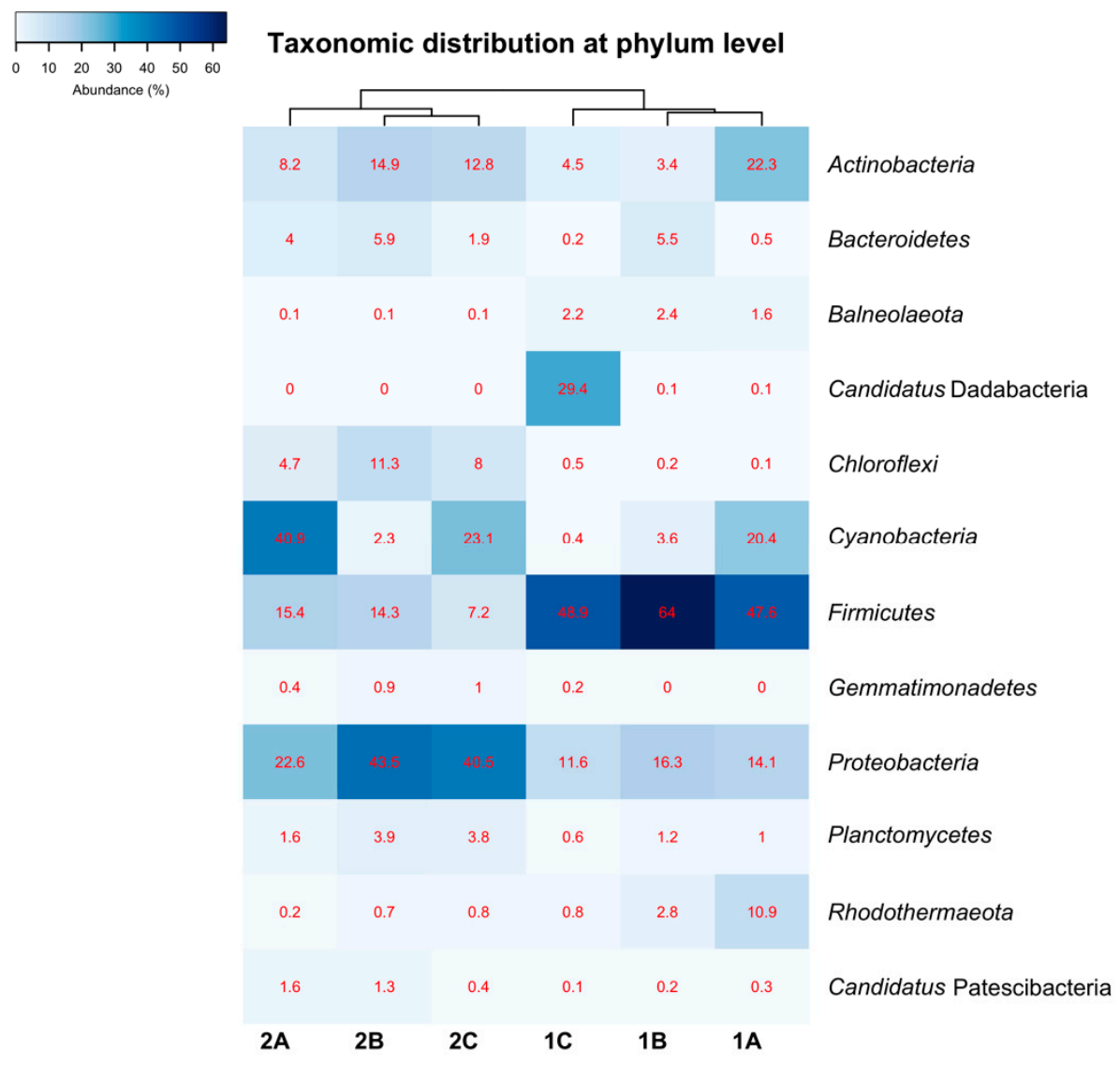

Figure 2. Heat-map analysis of Nerja Cave biofilms. Taxonomic identifications of Bacteria at phylum level. The phyla are described in the right column and their respective abundances included in the boxes. 
In a range of lower abundance were the phyla 'Candidatus Dadabacteria', which only reached significant representation in sample 1C, and Actinobacteria, in samples 1A, 2B and 2C. They were followed in abundance by the phylum Chloroflexi in sample 2B and Rhodothermaeota in sample 1A. The phylum Bacteroidetes was relatively well represented in samples $1 \mathrm{~B}$ and 2B. Planctomycetes reached significant percentages in samples 2B and 2C, followed by Balneolaeota in samples 1B and 1C. Finally, the superphylum Patescibacteria reached percentages higher than $1 \%$ in samples $2 \mathrm{~A}$ and $2 \mathrm{~B}$. The Gemmatimonadetes phylum was represented in sample 2 with percentages $\leq 1 \%$.

Figures 3 and 4 illustrate the bacterial diversity at the class and order levels. The communities of the two speleothems showed a high heterogeneity in abundance, depending on the location area (biofilm, without biofilm, and interface area), with high percentages in the classes Bacilli and Cyanophyceae (Figure 3).

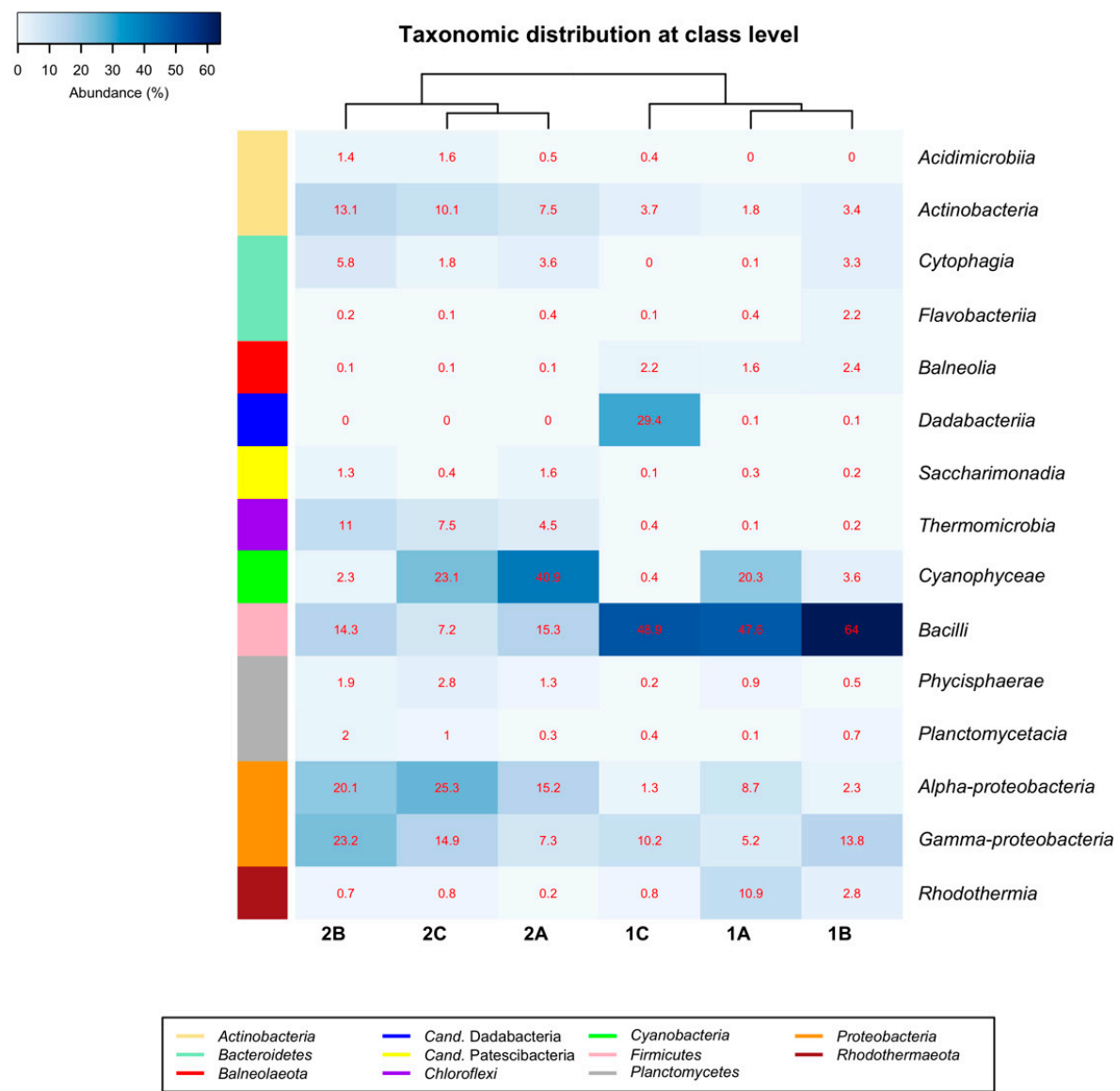

Figure 3. Heat-map analysis of Nerja Cave biofilms. Taxonomic identifications of Bacteria at class level. The classes are described in the right column and their respective abundances included in the boxes.

Considering all the six samples, the most abundant classes (those that at least reached a value greater than 5\% in a sample) were Bacilli, Cyanophyceae, Alphaproteobacteria, Gammaproteobacteria, Dadabacteriia, Actinobacteria, Thermomicrobia, Rhodothermia and Cytophagia.

The phylum Firmicutes and the class Bacilli was one of the most abundant in samples 1 and 2. The order Bacillales comprised two genera: Bacillus and Psychrobacillus. The genus Bacillus was the most abundant in sample 1, while in sample 2 the abundance of Bacillus fell between six and three times, with respect to sample 1 . 


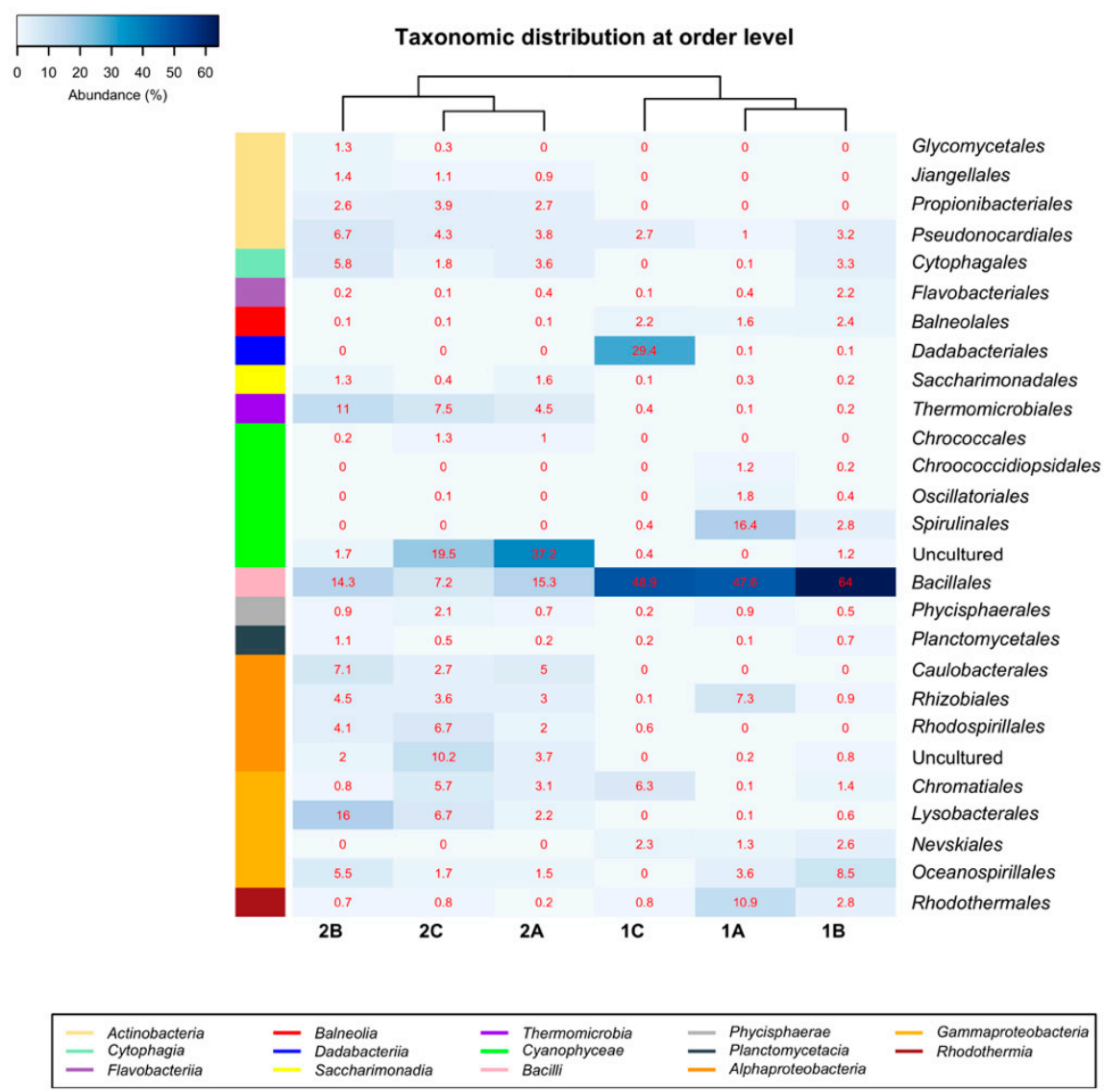

Figure 4. Heat-map analysis of Nerja Cave biofilms. Taxonomic identifications of Bacteria at order level. The orders are described in the right column and their respective abundances included in the boxes.

Cyanobacteria, the phylum that contained the phototrophic microorganisms, only included two identified genera: Desertifilum and Spirulina (Figure 5). In sample 1A, Spirulinales showed a remarkable abundance, and decreased in samples 1B and 1C (Figure 4). High abundances of uncultured members of the class Cyanophyceae were detected in samples 2A and 2C (Figure 5). It was interesting to find an abundance of Spirulina in sample 1 and a total absence in sample 2. However, a high abundance of uncultured members of the class Cyanophyceae was detected in sample 2, but lacking in sample 1 . This pattern also occurred for the family Chroococcidiopsaceae, which was absent in sample 2, as well as for Aphanothecaceae, which was lacking in sample 1 (Figure 5).

The class Alphaproteobacteria was mainly composed of the orders: Rhizobiales, Caulobacterales, Rhodospirillales, and members of an uncultured order (Figure 4). In this class, only two genera were identified: Brevundimonas and Mesorhizobium (Figure 5).

The class Gammaproteobacteria was represented by the orders Lysobacterales, Oceanospirillales and Chromatiales, with high abundance in all samples, and by Nerskiales, solely present in sample 1 (Figure 4). The most representative genera within the Gammaproteobacteria were: Lysobacter, Halomonas, Woeseia and Luteimonas. Thioalbus, Salinisphaera and Halopeptonella were identified in low abundance (Figure 5).

The phylum Actinobacteria was composed of three classes (Acidimicrobiia, Actinobacteria and Rubrobacteria). However, only the class Actinobacteria attained a remarkable abundance in sample 2, with a noticeable richness of the order Pseudonocardiales. Regarding the genus level, Amycolatopsis, present in the samples $2 \mathrm{~B}$ and $1 \mathrm{~B}$, and an uncultured genus of the family Nocardioidaceae, in samples $2 \mathrm{C}$ and 2A, showed relative abundance. The rest of genera (Crosiella, Yuhushiella, Pseudonocardia, Actinophytocola, Glycomyces and Halactinopolyspora) reached low abundances. 
Within the Chloroflexi phylum, the class Thermomicrobia showed relatively high abundance in sample 2B. The orders Phycisphaerales and Planctomycetales, within the phylum Planctomycetes, reached scarce representation in the biofilm samples (Figure 4).

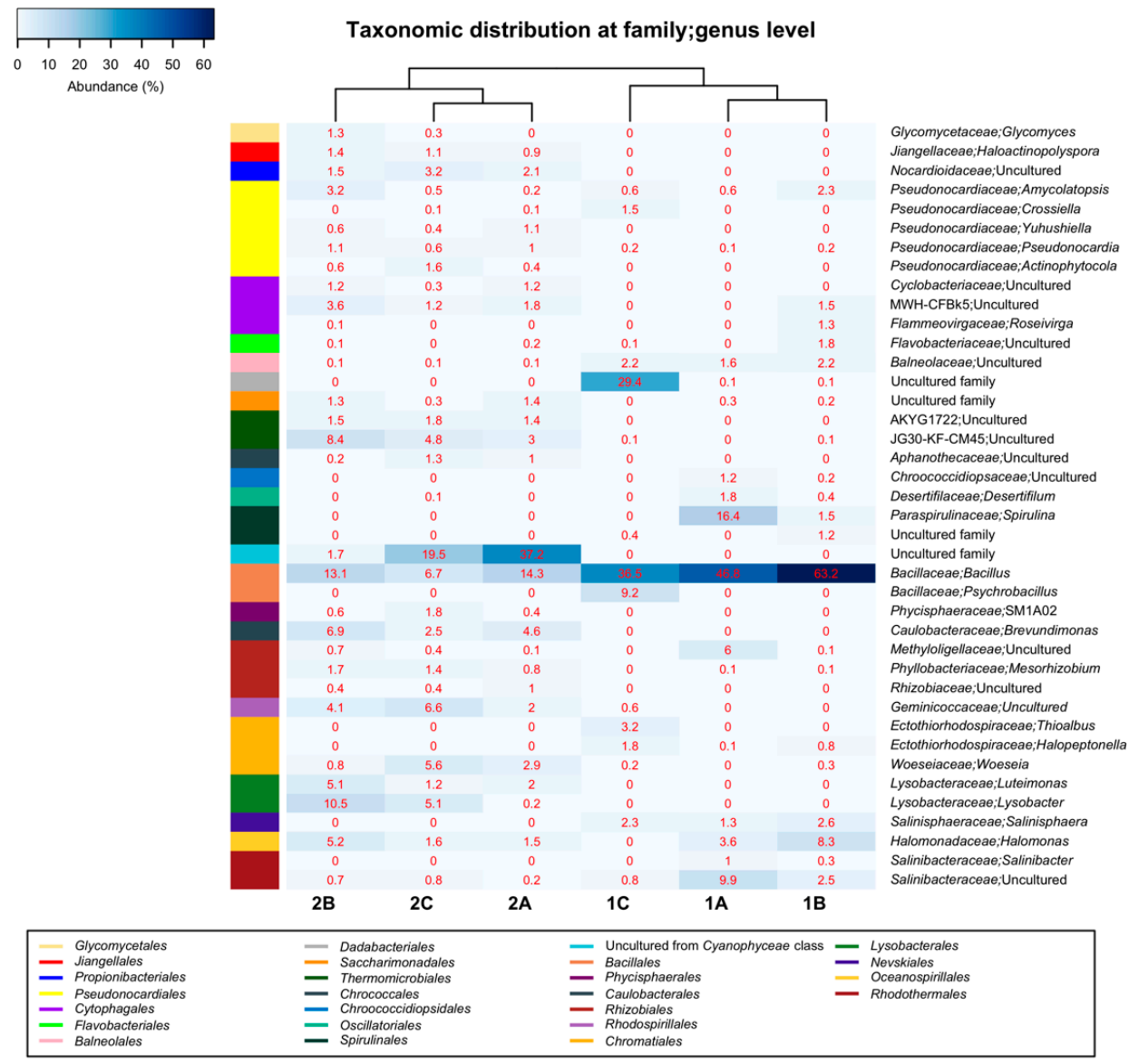

Figure 5. Heat-map analysis of Nerja Cave biofilms. Taxonomic identifications of Bacteria at families and genera level. The groups are described in the right column and their respective abundances included in the boxes.

A new phylum separated from Bacteroidetes is Rhodothermaeota [16], represented by the class Rhodothermia in sample 1A. This class comprises the genus Salinibacter, only found in sample 1A, together with other uncultured genera.

The phylum Bacteroidetes includes the class Cythophagia and the order Flavobacteriales, with uncultured genera, except for Roseivirga, with poor representation in all samples. The new phylum Balneolaeota [17], recently separated from Bacteroidetes, which includes the class Balneolia, only reached a representative abundance in sample 1.

The phyla 'Candidatus Dadabacteria', Gemmatimonadetes and the superphylum Patescibacteria were commonly represented by uncultured bacteria, in low percentages of abundance which can only be identified using NGS. The abundance of the order Dadabacteriales was remarkable in sample 1C (Figure 4).

Most of the eukaryotic sequences retrieved in sample 1 were unknown, while in sample 2 the percentage of unassigned sequences was notably lower (Table 2). 
Table 2. Relative abundance of eukaryotes, with higher taxonomic level in bold and lower taxonomic levels in italics.

\begin{tabular}{|c|c|c|c|c|c|c|}
\hline & & & \multicolumn{4}{|c|}{ Abundance of Sequences (\%) * } \\
\hline & & & $1 \mathrm{~A}$ & 1B & $2 \mathrm{~A}$ & 2B \\
\hline \multirow{7}{*}{ Amoebozoa } & \multirow[b]{4}{*}{ Schizoplasmodiida } & Dactylopodida & 17.7 & 2.6 & 0.0 & 0.0 \\
\hline & & Acanthamoeba & 0.0 & 0.0 & 1.2 & 6.0 \\
\hline & & Balamuthia & 0.0 & 0.0 & 0.4 & 1.1 \\
\hline & & uncultured & 0.0 & 4.7 & 46.2 & 40.8 \\
\hline & Tubulinea & Echinamoebida & 10.5 & 0.4 & 0.0 & 0.0 \\
\hline & uncultured & uncultured & 6.8 & 8.3 & 0.0 & 0.0 \\
\hline & Others & uncultured & 0.0 & 0.0 & 1.2 & 0.0 \\
\hline \multirow{4}{*}{ Opisthokonta } & \multirow{2}{*}{ Holozoa } & Codonosigidae & 0.0 & 0.0 & 0.5 & 8.5 \\
\hline & & Rhabditida & 0.0 & 0.0 & 12.4 & 19.1 \\
\hline & \multirow{2}{*}{ Fungi } & Stachybotryaceae & 0.0 & 0.0 & 0.0 & 3.2 \\
\hline & & uncultured & 0.2 & 0.2 & 0.2 & 1.4 \\
\hline \multirow{7}{*}{ SAR } & \multirow{3}{*}{ Alveolata } & Gregarina & 6.4 & 3.8 & 0.5 & 1.3 \\
\hline & & uncultured & 0.0 & 0.0 & 1.7 & 0.0 \\
\hline & & Colpodea & 0.0 & 0.0 & 4.2 & 3.3 \\
\hline & \multirow[t]{2}{*}{ Rhizaria } & Heteromita & 0.0 & 0.0 & 12.2 & 8.2 \\
\hline & & P34,6 & 0.0 & 0.0 & 0.0 & 2.9 \\
\hline & \multirow[t]{2}{*}{ Stramenopiles } & Sorodiplophrys & 0.4 & 0.7 & 5.8 & 1.6 \\
\hline & & Chlamydomyxa & 0.0 & 0.0 & 4.6 & 0.0 \\
\hline Unknown & Others & Others & 58.0 & 79.3 & 8.9 & 2.6 \\
\hline
\end{tabular}

The eukaryotic organisms identified in the four samples were affiliated to Amoebozoa, Opisthokonta and SAR. Table 2 shows the taxonomic composition of the samples where only the taxa represented with values greater than $1 \%$ were included.

Sample 1 was characterized by the abundance of Amoebozoa belonging to the order Dactylopodida, with uncultured members in sample $1 \mathrm{~A}$, an uncultured order in $1 \mathrm{~A}$ and $1 \mathrm{~B}$, and members of the family Echinamoebida in 1A. The genus Gregarina (SAR) was relatively abundant in samples 1A and 1B.

The sampling site 2 showed very high abundances in samples $2 \mathrm{~A}$ and $2 \mathrm{~B}$ for uncultured Schizoplasmodiida of the Amoebozoa supergroup, followed by uncultured members of the order Rhabditida. The genus Heteromita (Rhizaria) also appeared with significant abundance in samples 2A and 2B. The genus Acanthamoeba, uncultured members of the Codonosigidae family and the genus Sorodiplophrys (Stramenopiles) in sample 2A were also noticeable. Cultivable genera such as Balamuthia and Chlamydomyxa were also identified.

To summarize, within Bacteria, significant differences were found between the two biofilm samples collected from speleothems displaying abundant growth of phototrophic microorganisms. Considering taxonomic groups in proportions greater than $1 \%$, the analysis reflected a great diversity in the taxonomic composition of each sample, with a total of 27 orders (Figure 4). Comparatively, the samples presented similar orders, and shared common groups. Thus, samples 1 and 2 shared 22 orders. The greatest differences between each sample were in the percentage of abundance of certain groups, among which an uncultured order of Alphaproteobacteria, Rhizobiales, Oceanospirillales, Chromatiales, Rhodothermales, Dadabacteriales, Bacillales and the phototrophic Spirulinales were remarkable in sample 1, while the abundances of Rhodospirillales, Caulobacterales, Lysobacterales, Thermomicrobiales, Pseudonocardiales, Cytophagales, Bacillales and uncultured members of the phototrophic Cyanophyceae were noticeable in sample 2.

The Eukaryota showed a total of 19 groups, of which 7 were found in sample 1, and 16 in sample 2. Both sampling sites solely shared 5 groups of eukaryotes: Schizoplasmodiida, uncultured Amoebozoa 
uncultured Fungi, and the genera Gregarina and Sorodiplophrys. In addition, the high abundance of unassigned sequences in sample 1 indicated the existence of large unknown taxa in this community.

\section{Discussion}

Phototrophic microorganisms, such as cyanobacteria and algae, are usually found on speleothems, rocks and walls washed by percolation water or in the vicinity of light sources. The development of cyanobacteria and algae, which can be considered as primary colonizers, is usually influenced by the availability of light, water and dissolved mineral elements. The development of a photosynthetic-based biofilm may lead to the formation of a more complex ecosystem, because phototrophic microorganisms release extracellular compounds, which favor the establishment of heterotrophic bacteria. In later phases of the community, fungi, protozoa and metazoans will appear, giving rise to a complex community with important trophic interactions.

The formation of plaques or spots where the detachment of phototrophic microorganisms was evident, as found in Nerja Cave, can be assumed on the basis of processes of predation of some microorganisms on others. The samples labeled B and C in the two biofilms analyzed presented detachments indicative of some type of action (lysis, predation, etc.) on the cyanobacteria with respect to the intact biofilm (labeled A).

It is interesting to note that while the cyanobacterium Spirulina reached a remarkable abundance in sample 1A, it disappeared in sample 1C (complete detachment) and its concentration decreased six times in sample 1B (intermediary phase) with respect to $1 \mathrm{~A}$. This would indicate that the population of Spirulina has been predated by other microorganisms. Other groups and genera of cyanobacteria are minority in sample 1 (Desertifilum, Chroococcidiopsaceae and uncultured members of Cyanophyceae) and disappeared in the detached area (sample 1C).

The cyanobacterial composition of sample 2 is completely different. In this case, the most abundant cyanobacterium was not Spirulina, absent in these biofilms, but unidentified members of the class Cyanophyceae. Comparing the retrieved sequences with the NCBI database, we found that these unidentified members were related, although with a low percentage of similarity $(87 \%)$ with Loriellopsis cavernicola. In sampling site 2 , the detachment or loss of the biofilm occupies large areas, suggesting that the process of predation was much more pronounced. This is compatible with the high abundance of eukaryotes.

The richness of Bacillus in sample 1B was remarkable, although it was also present in considerable abundance in all other samples. Members of the phylum Firmicutes, and in particular the genus Bacillus, are well represented in caves $[18,19]$.

The presence of Bacillus in Nerja Cave biofilms can be due to: (i) species of the genus Bacillus (B. cereus, B. mycoides) can lyse different species of cyanobacteria [20-23], and contributed to their disappearance (detached areas); or (ii) the periodic processes of humidification and desiccation suffered by the phototrophic biofilms. A similar process has been described by Karaoz et al. [23] for biological soil crusts dominated by cyanobacteria. In this case, the communities are well adapted to survive desiccation and quickly take advantage of rainfall periods, producing a bloom of Firmicutes, mainly of the order Bacillales (Bacillus spp.). This does not preclude a lytic activity.

The existence of a high number of Dadabacteria sequences in sample 1C is an unprecedented fact and reflects the poor existing knowledge about cave microbial ecology, and the microbial strategies necessary to growth and proliferate in cave conditions. Dadabacteria is a recently proposed candidate phylum, previously known as CSP1-2, and rarely present in environmental samples. These aerobic bacteria have been identified through metagenomic analysis [24]. The genome encodes glycolysis, a complete Krebs cycle and an electron transport chain for oxidative phosphorylation that includes a cytochrome c oxidase and possibly intervention in the nitrogen and sulfur cycles [24]. There is no information about a possible lytic activity on cyanobacteria or an explanation for their abundance. 
Regarding eukaryotes, sample 1 showed abundance of uncultured Amoebozoa groups, such as the lobose amoebas of the order Dactylopodida that ingest cyanobacteria, algae, bacteria, yeasts and particulate matter, as well as Echinamoebida, and other group without assignment.

Protozoa are traditionally considered the main predators of bacteria, as this is a lifestyle common to this group. Predatory protozoa exist in both aquatic and terrestrial environments and represent a major component in nutrient remineralization or 'microbial loop.' Dryden and Wright [25] reported a list of protozoa (including Amoebozoa) that predated on a wide variety of cyanobacterial species (Anabaena, Nostoc, Microcystis, Oscillatoria, Gloeocapsa, Phormidium, Lyngbya, Synechococcus, etc.).

The genus Gregarina of the SAR supergroup was abundant in sampling site 1. According to Clopton et al. [26] there are more than 300 species of Gregarina that mainly infect coleoptera and orthoptera, but also colembola, diptera, lepidoptera, hymenoptera, etc. The presence of parasitic gregarins, in sample 1, must be related to the population of insects in the cave, since they have a great abundance of parasitic species.

Jurado et al. [27] identified in various samples of Nerja Cave sequences of the species Gregarina blattarum. Gregarina blattarum has been found in different species of cockroaches: Blatta orientalis, Periplaneta americana, Periplaneta discoidales, Blattella germanica, Parcoblatta pennsylvanica and Blaberus craniifer and is the most widely studied species of Gregarina [28].

A review of the literature reveals a series of predatory bacteria on cyanobacteria and algae, mainly the genera Lysobacter, Bacillus, Cytophaga, Myxobacteria, Herpetosiphon, Ensifer, Vampirococcus, Vampirovibrio, Cupriavidus, Pseudomonas, Stenotrophomonas, Acinetobacter and Delftia [22,29-31]. From all these genera, in sample 2 were present Lysobacter, Bacillus and uncultured members of the order Cytophagales, not being able to rule out the possible existence of other bacteria with similar capacities from the extensive list of uncultured members.

From the NGS analysis, the possible predatory activity and implication of Lysobacter in sample 2 was evident. Reichenbach [32] found that the densities of cyanobacterial and lytic bacteria populations correlated well and that bacteria attacked cyanobacteria in two ways, by excreting exoenzymes or by fixing them to the cell. Puopolo et al. [33] studied the Lysobacter genome confirming the ability to produce proteolytic enzymes. In addition, the genome revealed the presence of a high number of genes encoded for proteases, endopeptidases and metalloendopeptidases. The genus Bacillus was also abundant in sample 2 and could reinforce the predatory activity on this sample.

Considering the analysis of eukaryotes, the uncultured members of Schizoplasmodiida (Amoebozoa) stand out in sample 2. This group of protosteloid amoebas is predator of bacteria and fungi in terrestrial ecosystems, where they have a global distribution [34]. The genus Acanthamoeba (Amoebozoa) was present in sample 2B. Cyanobacteria are an adequate food source for amoebas, ciliates and flagellates, among the first is notable the genus Acanthamoeba and the species A. castellanii [35,36]. Acanthamoeba castellanii were found in some other caves $[37,38]$.

Ma et al. [35] evaluated the capacity of five amoebas, among them A. castellanii, on the cyanobacteria Synechococcus elongatus, Leptolyngbya sp. and Anabaena sp., demonstrating a predatory activity. Wright et al. [36] showed that $A$. castellanii consumed unicellular and filamentous cyanobacteria. Predation was initiated by complete engulfment of the unicellular cyanobacterium and, in the case of the filamentous, by rupture of the filaments, followed by digestion in the vacuoles.

Important abundances reached the nematodes of the order Rhabditida in samples 2A and 2B, the uncultured members of the family Codonosigidae (Choanoflagellida, Opisthokonta), flagellates of the genus Heteromita (Rhizaria), one of the most important predators of bacteria in aquatic ecosystems, and uncultured ciliates of the class Colpodea.

Finally, in sample 2A the amoeboid protist of the genus Sorodiplophrys (Labyrinthulomycetes, Stramenopiles) and Chlamydomyxa (Ochrophyta, Stramenopiles), a photophagotrophic ameboid alga, were noticeable.

Abolafia and Peña-Santiago [39] carried out a review of the order Rhabditida of nematodes in Spain, finding 80 species belonging to 40 genera and 12 families, of which six species were found in the 
province of Malaga. These nematodes are frequent in soils and waters, however, the sequences found in sample 2 belong to unidentified genera.

It is noteworthy the presence of ciliates, flagellates, amoebas and nematodes in sampling site 2, which implies that this biofilm conforms a complex ecosystem where a high dependence between prey and predators has been established. Apart from the microorganisms that act as predators, there are others that can act as saprophytes, feeding on decomposing organic matter.

\section{Conclusions}

The study of two phototrophic biofilms developed on the speleothems of Nerja Cave showed different structures and hence diverse predators. This indicated complex trophic interactions between the components of the biofilms. The question is how many different biofilms and predators are in this cave? This should be responded in future studies with a larger number of biofilm samples in different ecological scenarios, if further sampling is possible.

This study evidences that a natural biological control exists in caves and it could be a new method of control to be tested and used if the growth of predatory populations is enhanced. This research represents a first attempt to investigate the potentialities of the biological control of photosynthetic-based biofilms in caves.

Author Contributions: Conceptualization and work design, Y.d.R.; methodology, analyses and investigation, V.J., B.H. and J.L.G.-P.; writing, review and editing, C.S.-J. All authors have read and agreed to the published version of the manuscript.

Funding: This research was funded by Nerja Cave Foundation.

Acknowledgments: The authors acknowledge Nerja Cave Foundation for the support and facilities. The authors also acknowledge A.Z. Miller for the English language corrections.

Conflicts of Interest: The authors declare no conflict of interest.

\section{References}

1. Jurado, V.; Hernández-Mariné, M.; Rogerio-Candelera, M.A.; Domínguez-Moñino, I.; Gutiérrez-Patricio, S.; Sáiz-Jiménez, C. La Cueva del Tesoro: Un paraíso microbiano. In Cuevatur 2014, Iberoamerica Subterránea; Calaforra, J.M., Durán, J.J., Eds.; Asociación de Cuevas Turísticas Españolas: Madrid, Spain, 2014; pp. 431-441.

2. Albertano, P.; Moscone, D.; Palleschi, G.; Hermosín Campos, B.; Saiz-Jimenez, C.; Sánchez-Moral, S.; Hernández-Mariné, M.; Urzì, C.; Groth, I.; Shroeckh, V.; et al. Cyanobacteria attack rocks (CATS): Control and preventive strategies to avoid damage caused by cyanobacteria and associated microorganisms in Roman hypogean monuments. In Molecular Biology and Cultural Heritage; Saiz-Jimenez, C., Ed.; Balkema Pub.: Lisse, The Netherlands, 2003; pp. 151-162.

3. Liñán, C.; del Rosal, Y.; Carrasco, F.; Vadillo, I.; Benavente, J.; Ojeda, L. Highlighting the importance of transitional ventilation regimes in the management of Mediterranean show caves (Nerja-Pintada system, southern Spain). Sci. Total Environ. 2018, 631-632, 1268-1278. [CrossRef]

4. Ariño, X.; Hernandez-Marine, M.; Saiz-Jimenez, C. Colonization of Roman tombs by calcifying cyanobacteria. Phycologia 1997, 36, 366-373. [CrossRef]

5. Saiz-Jimenez, C. Biogeochemistry of weathering processes in monuments. Geomicrobiol. J. 1999, 16, 27-37. [CrossRef]

6. Saiz-Jimenez, C.; Cuezva, S.; Jurado, V.; Fernandez-Cortes, A.; Porca, E.; Benavente, D.; Cañaveras, J.C.; Sanchez-Moral, S. Paleolithic art in peril: Policy and science collide at Altamira Cave. Science 2011, 334, 42-43. [CrossRef]

7. Mulec, J.; Kosi, G. Lampenflora algae and methods of growth control. J. Cave Karst Stud. 2009, 71, 109-115.

8. Baquedano Estévez, C.; Moreno Merino, L.; de la Losa Román, A.; Durán Valsero, J.J. The lampenflora in show caves and its treatment: An emerging ecological problem. Int. J. Speleol. 2019, 48, 249-277. [CrossRef]

9. Smith, T.; Olson, R. A taxonomic survey of Lamp Flora (Algae and Cyanobacteria) in electrically lit passages within Mammoth Cave National Park, Kentucky. Int. J. Speleol. 2007, 36, 105-114. [CrossRef] 
10. Del Rosal Padial, Y.; Jurado Lobo, V.; Hernández Mariné, M.; Roldán Molina, M.; Sáiz Jiménez, C. Biofilms en cuevas turísticas: La Cueva de Nerja y la Cueva del Tesoro. In El Karst y el Hombre: Las Cuevas como Patrimonio Mundial; Andreo, B., Durán, J.J., Eds.; Asociación de Cuevas Turísticas Españolas: Madrid, Spain, 2016; pp. 103-114.

11. Cennamo, P.; Marzano, C.; Ciniglia, C.; Pinto, G.; Cappelletti, P.; Caputo, P.; Pilio, A. A survey of the algal flora of anthropogenic caves of Campi Flegrei (Naples, Italy) archeological district. J. Cave Karst Stud. 2012, 74, 243-250. [CrossRef]

12. Lamprinou, V.; Danielidis, D.B.; Economou-Amilli, A.; Pantazidou, A. Distribution survey of Cyanobacteria in three Greek caves of Peloponnese. Int. J. Speleol. 2012, 41, 267-272. [CrossRef]

13. Rittmann, B.E. Detachment from biofilms. In Structure and Function of Biofilms; Characklis, W.G., Wildered, P.A., Eds.; John Wiley \& Sons: Chichester, UK, 1989; pp. 49-58.

14. Bradley, I.M.; Pinto, A.J.; Guest, J.S. Design and evaluation of Illumina MiSeq-compatible, 18S rRNA gene-specific primers for improved characterization of mixed phototrophic communities. Appl. Environ. Microbiol. 2016, 82, 5878-5891. [CrossRef]

15. Warnes, G.R.; Bolker, B.; Bonebakker, L.; Gentleman, R.; Liaw, W.H.A.; Lumley, T.; Maechler, M.; Magnusson, A.; Moeller, S.; Schwartz, M.; et al. GPLOTS: Various R Programming Tools for Plotting Data. $\quad R$ Package, version 2.17.0; GitHub, Inc.: San Francisco, CA, USA, 2015; Available online: http://CRAN.R-project.org/package=gplots (accessed on 10 February 2020).

16. Muñoz, R.; Rosselló-Móra, R.; Amann, R. Revised phylogeny of Bacteroidetes and proposal of sixteen new taxa and two new combinations including Rhodothermaeota phyl. nov. Syst. Appl. Microbiol. 2016, 39, 281-296. [CrossRef] [PubMed]

17. Hahnke, R.L.; Meier-Kolthoff, J.P.; García-López, M.; Mukherjee, S.; Huntemann, M.; Ivanova, N.N.; Woyke, T.; Kyrpides, N.C.; Klenk, H.-P.; Göker, M. Genome-based taxonomic classification of Bacteroidetes. Front. Microbiol. 2016, 7, 2003. [CrossRef] [PubMed]

18. Fernandez-Cortes, A.; Cuezva, S.; Sanchez-Moral, S.; Porca, E.; Jurado, V.; Saiz-Jimenez, C. Detection of human-induced environmental disturbances in a show cave. Environ. Sci. Pollut. Res. 2011, 18, 1037-1045. [CrossRef] [PubMed]

19. Saiz-Jimenez, C. The microbiology of show caves, mines tunnels and tombs: Implications for management and conservation. In Microbial Life of Cave Systems; Engel, A.S., Ed.; DeGruiter: Berlin, Germany, 2015; pp. 231-261.

20. Nakamura, N.; Nakano, K.; Sugiura, N.; Matsumura, M. A novel cyanobacteriolytic bacterium, Bacillus cereus, isolated from a eutrophic lake. J. Biosci. Bioeng. 2003, 95, 179-184. [CrossRef]

21. Gumbo, R.J.; Ross, G.; Cloete, E.T. Biological control of Microcystis dominated harmful algal blooms. Afr. J. Biotechnol. 2008, 7, 4765-4773.

22. Gumbo, R.J.; Cloete, E.T. Light and electron microscope assessment of the lytic activity of Bacillus on Microcystis aeruginosa. Afr. J. Biotechnol. 2011, 10, 8054-8063. [CrossRef]

23. Reim, R.L.; Shane, M.S.; Cannon, R.E. The characterization of Bacillus capable of blue green bactericidal activity. Can. J. Microbiol. 1974, 20, 981-986. [CrossRef]

24. Hug, L.A.; Thomas, B.C.; Sharon, I.; Brown, C.T.; Sharma, R.; Hettich, R.L.; Wilkins, M.J.; Williams, K.H.; Singh, A.; Banfield, J.F. Critical biogeochemical functions in the subsurface are associated with bacteria from new phyla and little studied lineages. Environ. Microbiol. 2016, 18, 159-173. [CrossRef]

25. Dryden, R.C.; Wright, S.J.L. Predation of cyanobacteria by protozoa. Can. J. Microbiol. 1987, 33, 471-482. [CrossRef]

26. Clopton, R.E.; Cook, T.J.; Cook, J.L. Gregarina tropica n. sp. (Apicomplexa: Eugregarinorida: Gregarinicae: Gregarinidae) parasitizing the brown-winged earwig, Vostox brunneipennis (Dermaptera: Labiidae), in the Texas Big Thicket. Comp. Parasitol. 2008, 75, 215-227. [CrossRef]

27. Jurado, V.; Del Rosal, Y.; Hernández-Mariné, M.; Galocha Zapata, I.; Domínguez-Moñino, I.; Rogerio Candelera, M.A.; Sáiz-Jiménez, C. Biología molecular de los biofilms fotosintéticos de la Cueva de Nerja. In Análisis, Impacto y Evolución de los Biofilms Fotosintéticos en Espeleotemas. El caso de la Cueva de Nerja (Málaga, España); Del Rosal Padial, Y., Ed.; Fundación Pública de Servicios Cueva de Nerja: Nerja, Spain, 2017; pp. 229-270. 
28. Clopton, R.E.; Gold, R.E. Host specificity of Gregarina blattarum von Siebold, 1839 (Apicomplexa: Eugregarinida) among five species of domiciliary cockroaches. J. Invert. Pathol. 1996, 67, $219-223$. [CrossRef] [PubMed]

29. Christensen, P.; Cook, F.D. Lysobacter, a new genus of nonfruiting, gliding bacteria with a high base ratio. Int. J. Syst. Bacteriol. 1978, 28, 367-393. [CrossRef]

30. Rashidan, K.K.; Bird, D.F. Role of predatory bacteria in the termination of a cyanobacterial bloom. Microb. Ecol. 2001, 41, 97-105. [CrossRef] [PubMed]

31. Osman, O.A.; Beier, S.; Grabherr, M.; Bertilsson, S. Interactions of freshwater cyanobacteria with bacterial antagonists. Appl. Environ. Microbiol. 2017, 83, e02634-16. [CrossRef] [PubMed]

32. Reichenbach, H. The genus Lysobacter. In The Prokaryotes; Dworking, M., Falkow, S., Rosenberg, E., Schleifer, K.-H., Stackebrandt, E., Eds.; Springer: New York, NY, USA, 2006; Volume 6, pp. 939-957.

33. Puopolo, G.; Tomada, S.; Pertot, I. The impact of the omics era on the knowledge and use of Lysobacter species to control phytopathogenic microorganisms. J. Appl. Microbiol. 2017, 124, 15-27. [CrossRef] [PubMed]

34. Aguilar, M.; Lado, C. Check-list of microscopic protosteloid amoebae from the Southwest of Europe. Anales Jard. Bot. Madrid 2012, 69, 217-236. [CrossRef]

35. Ma, A.T.; Daniels, E.F.; Gulizia, N.; Brahamsha, B. Isolation of diverse amoebal grazers of freshwater cyanobacteria for the development of model systems to study predator prey interaction. Algal Res. 2016, 13, 85-93. [CrossRef]

36. Wright, S.J.L.; Redhead, K.; Maudsleys, H. Acanthamoeba castellanii, a predator of Cyanobacteria. J. Gen. Microbiol. 1981, 125, 293-300. [CrossRef]

37. Walochnik, J.; Mulec, J. Free-living amoebae in carbonate precipitating microhabitats of karst caves and a new vahlkampfiid amoeba, Allovahlkampfia spelaea gen. nov., sp. nov. Acta Protozool. 2009, 48, 25-33.

38. Garcia-Sanchez, A.M.; Ariza, C.; Ubeda, J.M.; Martin-Sanchez, P.M.; Jurado, V.; Bastian, F.; Alabouvette, C.; Saiz-Jimenez, C. Free-living amoebae in sediments from the Lascaux Cave in France. Int. J. Speleol. 2013, 42, 9-13. [CrossRef]

39. Abolafia, J.; Peña-Santiago, R. Rhabditid species (Nematoda, Rhabditida) recorded in peninsular Spain and Balearic islands. Graellsia 2001, 57, 113-131.

(C) 2020 by the authors. Licensee MDPI, Basel, Switzerland. This article is an open access article distributed under the terms and conditions of the Creative Commons Attribution (CC BY) license (http://creativecommons.org/licenses/by/4.0/). 